\title{
Percepções Identitárias no Reino Unido: Antes e depois do referendo Britânico
}

\author{
Identity Perceptions in United Kingdom: \\ Before and after the British referendum
}

DOI: $10.21530 /$ ci.v13n1.2018.759

Angélica Saraiva Szucko ${ }^{1}$

\section{Resumo}

No referendo de 23 de junho de 2016, 52\% da população do Reino Unido optaram pela saída da União Europeia. Em maio do mesmo ano, o país apresentou o maior percentual de identificação nacionalista entre os membros do bloco comunitário. Apesar da correlação observada, uma notável mudança ocorreu em novembro de 2016, com um aumento significativo, de aproximadamente catorze pontos percentuais, da identificação tanto como britânico quanto como europeu no país. Considerando que, em alguma proporção, a percepção identitária da população auxilia na compreensão das posições e das atitudes do governo britânico no seu relacionamento com a União Europeia, este artigo propõe uma análise sobre as percepções identitárias britânicas antes e depois do referendo de 2016. Por meio de uma análise diacrônica e comparativa dos dados das pesquisas de opinião do Eurobarometer, evidencia-se que o fraco sentimento de pertença ao bloco e o elevado sentimento nacionalista podem, em alguma medida, explicar o resultado do referendo britânico. Conclui-se que a identidade europeia funciona como um mecanismo de unificação na integração regional, e sua ausência ou a fragilidade tende a enfraquecer a relação entre o país e o bloco, como é o caso do Reino Unido.

Palavras-chave: Reino Unido; União Europeia; Percepções Identitárias; Referendo Britânico.

\begin{abstract}
In the referendum held on June 23rd 2016, $52 \%$ of the UK population opted to leave the European Union. In May of the same year, the country presented the highest percentage of nationalist identification among the members of the community bloc. Despite the observed

1 Professora na Universidade Federal de Goiás/UFG. Doutoranda em Relações Internacionais na Universidade de Brasília/UnB. Mestre em Relações Internacionais pela UnB (2016).

Artigo submetido em 25/01/2018 e aprovado em 14/04/2018.
\end{abstract}


correlation, a notable change occurred in November 2016 with a significant increase of approximately fourteen percentage points in both British and European identification in the country. Considering that, to a certain degree, the identity perception of the population helps to understand the positions and attitudes of the British government in its relationship with the European Union, this article proposes an analysis of British identity perceptions before and after the 2016 referendum. Based on a diachronic and comparative analysis of Eurobarometer opinion polls data, we demonstrate that the weak feeling of belonging to the bloc and the high nationalist sentiment may, to some extent, explain the outcome of the British referendum. We concluded that the European identity functions as a unifying mechanism in regional integration, and the absence or fragility of that identity tends to weaken the relationship between the country and the bloc, as in the case of the United Kingdom.

Keywords: United Kingdom; European Union; Identity Perceptions; British Referendum.

\section{Introdução}

Em 23 de junho de 2016, os cidadãos britânicos votaram em um plebiscito² sobre a saída do Reino Unido da União Europeia, no qual tiveram de responder ao seguinte questionamento: “o Reino Unido deve permanecer como membro da União Europeia ou sair da União Europeia?” (tradução nossa) ${ }^{3}$. Aproximadamente $52 \%$ da população votou pela retirada do país do bloco regional, o que traz consequências tanto para o próprio país quanto para a integração europeia como um todo (BBC, 2017a). O resultado do referendo simboliza o ápice da tensão no relacionamento entre o Reino Unido e a Europa comunitária, um processo que sempre foi marcado por apreensão e por distanciamento.

Constituído por Inglaterra, por País de Gales, por Escócia e por Irlanda do Norte, o Reino Unido adentrou as comunidades europeias em 1973, no mesmo alargamento que admitiu a Irlanda e a Dinamarca, somando-se à Alemanha Ocidental, à Bélgica, à França, à Itália, a Luxemburgo e aos Países Baixos, países fundadores do bloco regional. Essa primeira expansão do processo de integração regional caracterizou-se pelo reforço da lógica intergovernamental, em detrimento

2 É importante ressaltar que o resultado da votação não foi vinculante e que a decisão popular precisou ser aprovada pelo Parlamento. No direito britânico, não há a mesma diferenciação entre os conceitos "referendo" e "plebiscito", como ocorre na legislação brasileira; por esse motivo, neste artigo, os termos serão utilizados como sinônimos.

3 Should the United Kingdom remain a member of the European Union or leave the European Union? (tradução nossa). 
de ambições mais supranacionalistas para o bloco comunitário. De acordo com Michael Bruter (2005), o momento de entrada de um país no processo de integração reflete, em alguma medida, a sua identificação com o mesmo, e o alargamento de 1973 pautou-se mais pela cooperação interestatal do que pela promoção de um projeto político e pela construção de um êthos europeu. Em momentos cruciais para o adensamento da integração europeia, esses três países negociaram opções de exclusão ("opt-outs"4), ou seja, mecanismos que garantem a não participação em um campo específico da estrutura europeia comum.

As tratativas para adesão britânica estenderam-se por muitos anos. Na década de 1950, o Reino Unido recusou-se a participar da Comunidade Econômica Europeia (CEE), instituída pelo Tratado de Roma, em 1957, tanto pela oposição à criação de uma união aduaneira conforme proposto no tratado quanto pela relevância das relações comerciais da Commonwealth. Por esse ângulo, observa-se que, desde o princípio, o país não se coadunava com o propósito da integração europeia almejado pelos países precursores do bloco, uma vez que não manifestava vontade política na consolidação de instituições supranacionais que pudessem restringir sua soberania estatal.

Em contraposição à Comunidade Econômica Europeia, o governo britânico envolveu-se na criação da Associação Europeia de Livre-Comércio (European Free Trade Association - EFTA), em 1960, a qual constituía uma zona de livre comércio formada por Áustria, por Dinamarca, por Noruega, por Portugal, por Suécia e por Suíça; todavia, os resultados econômicos desse bloco não foram tão satisfatórios. No ano seguinte, o Reino Unido iniciou as negociações para adesão à CEE; não obstante, em 1963, o presidente francês Charles De Gaulle vetou a entrada britânica, temendo a forte aproximação desse país com os Estados Unidos, naquele momento da Guerra Fria. Em 1967, o Reino Unido foi novamente vetado por De Gaulle.

Somente após o fim do mandato do general francês, em 1969, as negociações foram retomadas; e, finalmente, em $1^{\circ}$ de janeiro de 1973, os britânicos entraram na CEE. Dessa forma, verifica-se que o relacionamento do Reino Unido com a Europa comunitária foi permeado de impasses, de tensões e de movimentos de resistência, o que pode ser exemplificado pelas opções de exclusão, por exemplo,

4 Também entendidos como derrogações. Opt-outs na União Europeia: o Acordo Schengen (Irlanda e Reino Unido); a União Econômica e Monetária (Dinamarca e Reino Unido); a Carta dos Direitos Fundamentais da União Europeia (Polônia e Reino Unido); e a Área de Liberdade, Segurança e Justiça (Dinamarca, Irlanda e Reino Unido). 
do Acordo Schengen ${ }^{5}$ e da Zona Euro. De fato, para o governo britânico, a União Europeia servia como um mecanismo para a promoção de seu interesse nacional, e o país sempre foi relutante em compartilhar sua soberania na construção de uma comunidade supranacional.

É interessante observar como o referendo britânico, em certa medida, se relaciona com a temática identitária. Nesse sentido, a pergunta que norteia este artigo é: como o resultado do referendo reflete as percepções identitárias no Reino Unido? De modo acessório, pretende-se também observar e comparar as mudanças nos aspectos identitários antes e depois da consulta popular realizada em junho de 2016. Nesse sentido, o artigo propõe uma análise sobre a histórica relação do Reino Unido com a União Europeia, bem como sobre a interação entre essas múltiplas identidades e seus reflexos tanto no resultado do referendo britânico quanto nas eleições gerais de 8 junho de 2017.

De maneira a atender a esse objetivo, o artigo será dividido em três partes e utilizar-se-á de uma breve revisão da literatura e da análise dos dados quantitativos das pesquisas de opinião do Eurobarometer. Primeiramente, com base na literatura sobre o Reino Unido e a União Europeia, serão enunciados alguns elementos do relacionamento entre ambos ao longo do processo de integração, de modo a complementar a introdução. Em segundo lugar, serão apontados a interação entre as múltiplas identidades no caso britânico, por meio de uma análise diacrônica baseada nos relatórios do Eurobarometer, e o modo como a baixa identificação com a União Europeia tende a enfraquecer o relacionamento do país com o bloco. Ademais, serão comparadas as informações das pesquisas de opinião realizadas antes e depois de junho de 2016. Em terceiro lugar, será realizada uma breve análise dos resultados do referendo, relacionando-os com as estratificações nos dados publicados pelo Eurobarometer. Além disso, são apresentados alguns comentários exploratórios sobre o resultado das eleições gerais para o Parlamento Britânico realizadas em 8 de junho de 2017. Ao final, com base nos dados apresentados, reitera-se o argumento do Michael Bruter (2005) de que a identidade europeia e o apoio à integração regional são variáveis correlacionadas, e conclui-se que a fragilidade da primeira tende a dificultar a relação entre o país e o bloco, como evidenciado pelo resultado do referendo no Reino Unido.

5 O Acordo Schengen refere-se a uma política de abertura de fronteiras e de livre circulação de pessoas entre os países signatários. Atualmente, 26 países fazem parte do acordo: Islândia, Liechtenstein, Noruega, Suíça e mais 22 dos 28 membros da União Europeia (Irlanda e Reino Unido mantêm a opção de exclusão, enquanto Bulgária, Croácia, Chipre e Romênia são legalmente obrigados a aderir ao acordo, pois o Tratado de Amsterdã o incorporou à legislação do bloco, contudo, ainda não o fizeram). 


\section{O relacionamento entre o Reino Unido e a União Europeia}

No que tange ao processo de integração europeia, o Reino Unido é um dos países mais reticentes e encontra dificuldades particulares em conciliar as políticas domésticas com as europeias, como no caso do opt-out do Acordo Schengen, o que reitera a política britânica de controle de fronteiras como uma prerrogativa que não deve ser compartilhada no nível comunitário. Segundo Bojana Perisic (2010), esse euroceticismo pode ser explicado por motivos históricos, aos quais ela dá maior destaque, e também por motivos tradicionais, institucionais e estratégicos. Do ponto de vista histórico, pode-se notar que a memória do império britânico e da expansão colonialista ainda tem grande influência na forma como as elites políticas visualizam a posição do país na Europa. Considerando que o Reino Unido moldou a história mundial por séculos, a autora afirma que não é surpresa que parte da sua população se sinta relativamente superior à de outros países europeus. Para essa parcela da população, vincular-se a instituições europeias significa, em alguma medida, perder essa influência global e reduzir o escopo de oportunidades para o nível europeu. Para Perisic (2010), esse aspecto histórico consiste em uma barreira psicológica que resulta em uma dificuldade notável no relacionamento entre o Reino Unido e a Europa comunitária.

Outro elemento que deve ser considerado é o fato de que o país não participou da criação das comunidades europeias. O governo de Clement Attlee (1945-1951) recusou-se a participar da negociação da Comunidade Econômica do Carvão e do Aço (CECA), formada em 1951. Ademais, em 1957, com o Tratado de Roma, foram criadas a Comunidade Econômica Europeia e a Comunidade Europeia de Energia Atômica (Euratom). Nesse sentido, diferente dos países fundadores, o Reino Unido não pôde opinar sobre as regras básicas estabelecidas e teve de adaptarse às mesmas quando decidiu participar do processo de integração. Conforme mencionado na introdução, a entrada do Reino Unido na CEE foi vetada duas vezes pela presidência francesa de De Gaulle e, apenas em 1973, o país adentrou as comunidades europeias.

É importante ressaltar que, desde o início, o Reino Unido não buscava estreitar a integração política e sempre foi relutante no que se refere à transferência de soberania, tendendo a optar por uma estrutura de cooperação intergovernamental. Anos após a entrada na CEE, os ganhos econômicos não corresponderam ao esperado, e o Partido Trabalhista inglês, liderado por Harold Wilson, realizou um referendo em 1975, a respeito da participação nas comunidades europeias. 
O resultado do referendo, em que a maioria da população (67\%) votou pela permanência na CEE, mudou o posicionamento do Partido Trabalhista em relação à integração europeia, que passou a assumir um tom mais favorável, especialmente quando certas temáticas sociais passaram a ser abordadas pela legislação europeia. No Partido Conservador, por sua vez, alguns políticos começaram a voltar-se contra a ideia da integração, o que ganhou maior força com Margaret Thatcher (PERISIC, 2010).

O período do governo Thatcher (1979-1990) foi marcado pelo isolamento político britânico da Europa. Durante seu mandato, foi assinado o Ato Único Europeu, em 1986, que estabelecia as bases para a formação de um mercado interno europeu; todavia, a primeira-ministra era abertamente contra o aprofundamento da integração política, econômica e social, pois entendia que o Reino Unido estava perdendo sua independência e sua soberania, ao transferir o poder decisório para as instituiçõoes europeias em Bruxelas. Para o Reino Unido, a unidade europeia consistia em um projeto meramente econômico, capaz de criar um mercado comum europeu, e não uma comunidade política. Por essas razões, o país decidiu, ao assinar o Tratado de Maastricht, em 1992, não participar da União Econômica e Monetária, o que significaria um aprofundamento para uma união política, bem como optou por não aderir ao Espaço Schengen (PERISIC, 2010).

Com a vitória do trabalhista Tony Blair, em 1997, houve um relativo movimento de aproximação com a Europa comunitária. Em sua campanha eleitoral, Blair anunciou que realizaria um referendo sobre a adoção do Euro, o qual não se efetivou. O então primeiro-ministro, entusiasmado com a União Europeia, assim que assumiu o cargo, assinou o capítulo social ${ }^{6}$ do Tratado de Maastricht; no entanto, o relacionamento especial do país com os Estados Unidos sempre causou desconfiança nos demais membros da União Europeia, que entendiam o bloco como um contrapeso à potência norte-americana. Essa aliança britânicoestadunidense ficou clara em 2001, quando, após os ataques de 11 de setembro, o Reino Unido declarou apoio direto aos Estados Unidos e enviou tropas para o Afeganistão e para o Iraque.

De fato, como aponta Perisic (2010, p. 9), existem inúmeros fatores que dificultam o relacionamento entre o Reino Unido e a União Europeia:

6 O capítulo social refere-se ao Protocolo sobre a política social e o Acordo sobre a política social, anexos do Tratado de Maastricht, os quais, até o momento, consistiam em opt-outs britânicos. 


\begin{abstract}
Existem inúmeros motivos que tornam problemática a participação britânica na União. Como um antigo poder imperial, o Reino Unido considera particularmente difícil ajustar e restringir seu interesse político apenas à Europa. Sendo um membro que adentrou mais tarde na Comunidade, teve de acomodar-se às políticas e às regras já estabelecidas, algumas das quais conflitam diretamente com os princípios básicos sobre os quais a constituição britânica se baseia. O antagonismo com a França e a afiliação com os Estados Unidos são questões adicionais. Além disso, o fato de que o Reino Unido se juntou à Comunidade apenas por razões econômicas em um momento economicamente difícil resultou em descontentamento popular. ${ }^{7}$ (tradução nossa)
\end{abstract}

Esses elementos apontados tendem a reforçar a ideia de que as ações políticas do Reino Unido, especialmente durante o governo Thatcher, fundamentam-se no nacionalismo britânico e na ideia de preservar a soberania e a autonomia do país frente ao projeto de integração europeia. Stephen George (1991), de maneira a contrabalancear tal perspectiva, apresenta o argumento de que as atitudes do governo britânico têm sido influenciadas pelo compromisso das elites políticoadministrativas tanto com o internacionalismo global (global internationalism) quanto com o nacionalismo. Além disso, George (1991) aponta que o aparente alinhamento com os Estados Unidos se relaciona com o compromisso de ambos os governos com uma perspectiva mais global de suas relações exteriores.

Com base nessa linha argumentativa, existiria uma relativa preocupação britânica com os motivos para a formação dos blocos regionais. Segundo George (1991), o Reino Unido, num primeiro momento, optou por não participar das comunidades europeias, acreditando que essas entrariam em colapso sem o seu apoio. Posteriormente, o país, ao pleitear a entrada na CEE, teria mudado de tática, mas não de estratégia, e esperava refrear o regionalismo europeu liderado por De Gaulle.

De modo a corroborar seu argumento de que as atitudes do Reino Unido estariam pautadas tanto em um internacionalismo global quanto no nacionalismo característico do país, Stephen George (1991) centra sua análise no discurso de Margaret Thatcher, em 1988, em Bruxelas. O trecho mais citado desse emblemático discurso de Thatcher aponta um forte caráter nacionalista: "França

7 There are numerous reasons which render British membership in the Union problematic. As a former imperial power, the UK finds it particularly difficult to adjust and narrow its political interest only to Europe. Being a latecomer in the Community, Britain had to accommodate itself to the already established policies and rules, some of which directly conflicted with the basic principles upon which the British Constitution is based. Antagonism with France and affiliation with America are additional issues. Furthermore, the fact that the UK joined the Community only for economic reasons at an economically difficult time resulted in popular discontent. 
como França, Espanha como Espanha, Grã-Bretanha como Grã-Bretanha, cada uma com seus próprios costumes, tradições e identidades”8 (THATCHER, 1988, p. 4, tradução nossa); todavia, segundo George (1991), tal passagem não pode ser interpretada de forma isolada do texto proferido pela então primeira-ministra britânica. O autor destaca outro trecho, que simbolizaria o internacionalismo britânico: “A Grã-Bretanha não sonha com uma existência acolhedora e isolada à margem da Comunidade Europeia. Nosso destino é na Europa, como parte da Comunidade (...) Isso não quer dizer que nosso futuro reside apenas na Europa" 9 (THATCHER, 1988, p. 3, tradução nossa).

Em síntese, o argumento de Stephen George (1991) é que a política britânica, ao mesmo tempo em que é influenciada pela necessidade de defender a soberania nacional parlamentar, também se compromete com outros valores, que derivam da posição do país no século XIX: a crença em uma economia liberal e o senso de que o Reino Unido tem uma missão internacional e uma responsabilidade especial de contribuir para a construção da ordem mundial. Esses valores são o que o autor denomina "compromisso com o internacionalismo global". Nesse sentido, o autor justifica a relutância britânica a um tipo de regionalismo que poderia desenvolver um bloco econômico relativamente fechado com matizes supranacionais e guiado por uma linha política que atende apenas aos interesses dos países membros.

Conforme observado, a resistência britânica ao processo de integração europeia é histórica e sempre esteve presente nas atitudes de diferentes governos. Considerando o argumento de Albert Hirschman (1970) ${ }^{10}$, em seu livro Exit, Voice and Loyalty, sobre o declínio das organizações ${ }^{11}$, segundo o qual os membros podem decidir vocalizar suas insatisfações ou sair da organização, os opt-outs do Reino Unido na União Europeia são compreendidos como instrumentos de vocalização do desinteresse no aprofundamento da integração e da preferência por mecanismos intergovernamentais, ao invés de supranacionais. Nessa perspectiva, o resultado da recente consulta popular simbolizaria a incapacidade de adaptação dos anseios

8 France as France, Spain as Spain, Britain as Britain, each with its own customs, traditions and identities.

9 Britain does not dream of some cosy, isolated existence on the fringes of the European Community. Our destiny is in Europe, as part of the Community (...) That's not to say that our future lies only in Europe.

10 Para uma análise mais atual utilizando o mesmo argumento, ver: HILMARSSON, 2017.

11 Entende-se que se trata de uma extrapolação do argumento do autor, mas já prevista pelo mesmo. "The argument to be presented starts with the firm producing saleable outputs for customers; but it will be found to be largely - and, at times, principally - applicable to organizations” (HIRSCHMAN, 1970, p. 3). 
nacionais aos comunitários e a decisão por retirar-se do processo de integração regional. Ademais, segundo Hirschman (1970), a escolha pela vocalização (voice) ou saída (exit) depende também do grau de lealdade (loyalty) do membro com a organização. Desta forma, a fraca identificação britânica com o projeto europeu elaborado pelos países fundadores contribui para o baixo senso de lealdade para com o mesmo e para sua relutância com o aprofundamento institucional. Em alguma medida, essa frágil lealdade reflete-se tanto nas atitudes dos governos, conforme explicitado anteriormente, quanto nas percepções identitárias da própria população do Reino Unido.

A análise das percepções identitárias britânicas, caracterizadas pelo elevado grau de nacionalismo e pelo baixo sentimento de identificação com a União Europeia, auxiliam na compreensão do relacionamento do país com o bloco comunitário. Como será exposto na seção seguinte, a identidade europeia fuciona como um mecanismo aglutinador na integração regional, e a ausência ou a debilidade daquela tende a enfraquecer a relação entre o país e o bloco, como é o caso do Reino Unido.

\section{A identificação britânica com a União Europeia}

Na literatura especializada sobre a temática de identidade europeia (RISSE, 2003, 2005; CHECKEL; KATZENSTEIN, 2009; FUCHS; KLINGEMANN, 2011), há um relativo consenso de que os indivíduos carregam identidades sociais múltiplas, ou seja, podem sentir-se parte de mais de uma identidade ao mesmo tempo. Isso significa que os indivíduos podem identificar-se ao mesmo tempo como europeus e britânicos, por exemplo. Dessa forma, o sentimento de identificação europeia não pressupõe o abandono das identidades nacionais, mas, sim, uma coexistência harmoniosa.

Os relatórios do Eurobarometer procuram, em alguma medida, assinalar essas possibilidades de identificação nos âmbitos nacional e europeu mediante o questionamento "Você se identifica como...?" (tradução nossa) ${ }^{12}$. As opções de resposta à pergunta são: apenas nacional; nacional e europeu; europeu e nacional; e apenas europeu, contemplando a ideia de identidades múltiplas. Segundo Michael

12 Do you see yourself as...? 
Bruter (2005), a identidade europeia e o suporte ao processo de integração regional são variáveis correlacionadas, o que, em certa medida, sugere uma relação entre a primeiro e a segundo. Dessa forma, quanto maior a identidade europeia, maior é o apoio ao processo de integração regional. Com base nos dados do Eurobarometer, é possível associar o baixo sentimento de identificação com a União Europeia às posições britânicas adotadas no referendo de 23 de junho de 2016.

De acordo com o Eurobarometer 85, no primeiro semestre de 2016, apenas $53 \%$ dos britânicos declararam-se cidadãos da União Europeia, abaixo da média europeia de 66\% (EUROPEAN COMMISSION, 2016a, p. 16). Esses dados não se alteraram de modo significativo nas pesquisas seguintes, realizadas em novembro de 2016 e maio de 2017, quando $55 \%$ e 54\% da população do Reino Unido afirmou sentir-se cidadã do bloco comunitário, em contraposição à média europeia de $67 \%$ e 68\%, respectivamente (EUROPEAN COMMISION, 2016b, p. 30; 2017, p. 38). Essa tendência inferior à média europeia tem-se apresentado ao longo dos anos no Reino Unido, conforme evidenciam a tabela e o gráfico abaixo, elaborados com base nos relatórios anuais do Eurobarometer desde 2012, a partir de quando houve uma sistematização na realização das pesquisas.

Tabela 1. Percentual de respostas em relação ao questionamento "Você se sente cidadão da União Europeia?"

mai/12 nov/12 mai/13 nov/13 mai/14 nov/14 mai/15 nov/15 mai/16 nov/16 mai/17

\begin{tabular}{|c|c|c|c|c|c|c|c|c|c|c|c|}
\hline \multicolumn{12}{|l|}{ Reino } \\
\hline $\begin{array}{l}\text { Unido } \\
\text { (Sim) }\end{array}$ & $42 \%$ & $48 \%$ & $48 \%$ & $42 \%$ & $52 \%$ & $50 \%$ & $56 \%$ & $52 \%$ & $53 \%$ & $55 \%$ & $54 \%$ \\
\hline Reino & & & & & & & & & & & \\
\hline $\begin{array}{l}\text { Unido } \\
\text { (Não) }\end{array}$ & $57 \%$ & $51 \%$ & $51 \%$ & $56 \%$ & $46 \%$ & $49 \%$ & $42 \%$ & $47 \%$ & $45 \%$ & $43 \%$ & $43 \%$ \\
\hline UE (Sim) & $61 \%$ & $63 \%$ & $62 \%$ & $59 \%$ & $65 \%$ & $63 \%$ & $67 \%$ & $64 \%$ & $66 \%$ & $67 \%$ & $68 \%$ \\
\hline UE (Não) & $38 \%$ & $36 \%$ & $37 \%$ & $40 \%$ & $34 \%$ & $35 \%$ & $31 \%$ & $34 \%$ & $33 \%$ & $32 \%$ & $31 \%$ \\
\hline
\end{tabular}

Fonte: elaboração da autora baseado em European Commission, 2012a, 2012b, 2013a, 2013b, 2014a, 2014b, 2015a, 2015b, 2016a, 2016b, 2017. 


\section{Gráfico 1. Percentual de respostas afirmativas em relação ao questionamento "Você se sente cidadão da União Europeia?"}

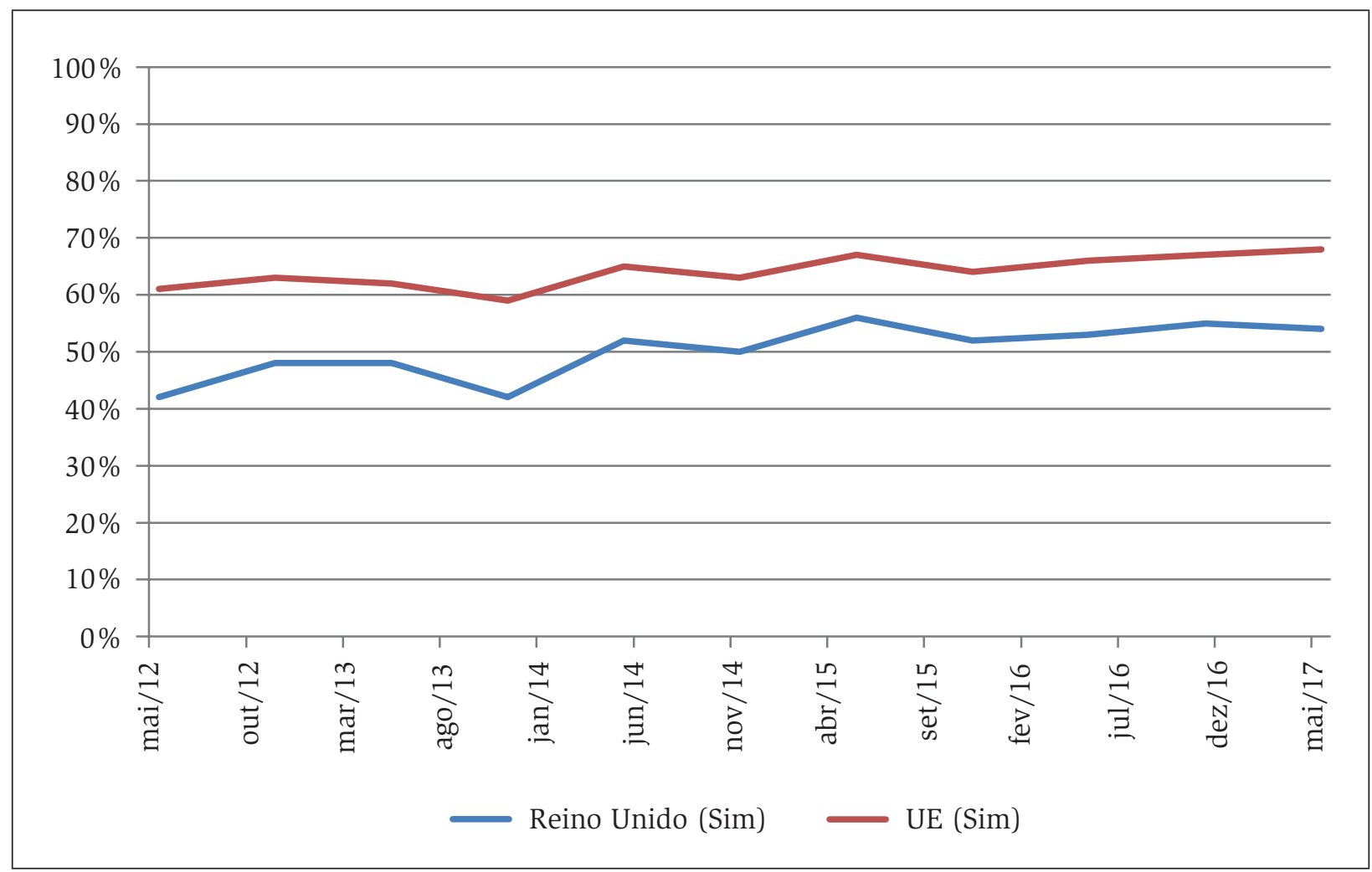

Fonte: elaboração da autora baseado em European Commission, 2012a, 2012b, 2013a, 2013b, 2014a, 2014b, 2015a, 2015b, 2016a, 2016b, 2017.

Ainda que se constate, nos últimos cinco anos, um aumento de aproximadamente dez pontos percentuais na parcela da população britânica que se identificou como cidadã da União Europeia, esse também foi um fenômeno observado, ainda que em menor medida, na média europeia, visto que, com o passar dos anos, há uma tendência de que as populações se sintam mais imersas no universo da integração regional. Apesar do crescimento no sentimento de identificação entre 2012 e início de 2017, o Reino Unido, como indica o gráfico, sempre esteve cerca de dez pontos percentuais abaixo da média europeia, o que evidencia o grau de distanciamento no relacionamento do país com o bloco e a dificuldade da população em se reconhecer como membro da União Europeia.

Conforme demonstrado, a identificação como cidadão da União Europeia não sofreu grandes alterações nas pesquisas antes e depois do referendo; todavia, no que se refere à categorização como "apenas nacional”, "nacional e europeu”, "europeu e nacional" e "apenas europeu”, observa-se uma mudança drástica nos dados dos relatórios. Ao responder à pergunta "Você se identifica como...?", na pesquisa realizada cerca de um mês antes do referendo, $62 \%$ dos britânicos escolheram 
a opção “apenas nacional”, maior valor registrado para essa opção entre todos os países membros da União Europeia no mesmo período. Aproximadamente, 31 \% escolheram a opção "nacional e europeu”; $3 \%$, a "europeu e nacional”; e $1 \%$, a “apenas europeu” (EUROPEAN COMMISSION, 2016a, p. 22). De fato, esses dados demonstram o fraco sentimento de pertença ao bloco comunitário e o elevado sentimento nacionalista que podem explicar o resultado final do referendo britânico com a vitória da opção pela saída da União Europeia.

Tabela 2. Percentual de respostas em relação ao questionamento

"Você se identifica como...?"

\begin{tabular}{ccccccccc}
\hline & mai/13 & nov/13 & mai/14 & nov/14 & mai/15 & nov/15 & mai/16 & nov/16 \\
\hline Apenas nacional & $60 \%$ & $63 \%$ & $64 \%$ & $58 \%$ & $64 \%$ & $66 \%$ & $62 \%$ & $48 \%$ \\
Nacional e europeu & $33 \%$ & $29 \%$ & $30 \%$ & $33 \%$ & $31 \%$ & $29 \%$ & $31 \%$ & $41 \%$ \\
Europeu e nacional & $3 \%$ & $3 \%$ & $2 \%$ & $4 \%$ & $2 \%$ & $3 \%$ & $3 \%$ & $6 \%$ \\
Apenas europeu & $2 \%$ & $1 \%$ & $1 \%$ & $2 \%$ & $1 \%$ & $1 \%$ & $1 \%$ & $2 \%$ \\
\hline
\end{tabular}

Fonte: elaboração da autora baseado em European Commission, 2013a, 2013b, 2014a, 2014b, 2015a, 2015b, 2016a, 2016b. ${ }^{13}$.

A Tabela 2 comprova o alto grau de nacionalismo britânico ao longo dos anos, mediante a escolha preponderante da opção "apenas nacional”; no entanto, uma notável mudança ocorreu justamente na pesquisa realizada após o referendo britânico, em novembro de 2016. Do primeiro para o segundo semestre de 2016, observa-se uma queda de catorze pontos percentuais na opção “apenas nacional”, a qual passou de $62 \%$, em maio, para $48 \%$, em novembro. Ademais, nesse mesmo período, registrou-se um aumento de dez pontos percentuais na opção "nacional e europeu", que saltou de $31 \%$ para $41 \%$, e de três pontos percentuais na "europeu e nacional", passando de $3 \%$ para 6\% (EUROPEAN COMMISSION, 2016b, p. 36). Em síntese, em menos de seis meses, 14\% da população britânica que, até então, autoafirmava-se como "apenas nacional", passou a identificar-se também como europeia, encaixando-se em outras categorias, a maioria delas, em identidades múltiplas que conciliam o sentimento de identificação nacional com a comunitária.

13 Os relatórios de 2012 não incluíam essa pergunta e os dados do relatório de 2017 ainda não estão disponíveis para esse tema. 
Ainda é difícil analisar o que essa drástica mudança, em um curto período de tempo, representa; todavia, essa deve ser considerada para estudos futuros sobre o relacionamento entre o Reino Unido e o bloco comunitário. Uma das possibilidades que se pode conjecturar é a de um movimento direto de reação ao resultado final do referendo pela saída da União Europeia, o que simbolizaria um arrependimento da população britânica, em alguma medida. Ademais, outra possibilidade é o desconhecimento da população do Reino Unido sobre o significado da União Europeia e sobre o processo de integração regional. Horas após a divulgação do resultado do referendo, houve um aumento no número de buscas na Internet pelos britânicos sobre o que seria a União Europeia (WASHINGTON POST, 2016). Essa tentativa de buscar uma melhor compreensão do que é esse bloco regional poderia ter-se refletido nos resultados do Eurobarometer do segundo semestre. Nesse sentido, uma população mais informada a respeito do que o processo de integração representa poderia, então, ao responder uma nova pesquisa, identificarse também como europeia, além de nacional. Após essa análise diacrônica sobre a evolução do sentimento de identificação britânica com a União Europeia, na seção seguinte serão apontadas como as divisões evidenciadas pelo resultado do referendo também estão expressas em aspectos identitários.

\section{Reflexos identitários no referendo britânico}

O resultado do referendo britânico revelou um cenário de um reino dividido. Segundo o jornalista Mark Easton da BBC, "o plebiscito revelou uma placa tectônica dividindo o Reino Unido. Uma ferida que dividiu a política e as estruturas sociais. Está longe de ficar claro se o reino ainda pode se declarar unido" (BBC BRASIL, 2016). Essa divisão pode ser compreendida em três dimensões principais: a política, a geográfica e a demográfica. Aqueles que apoiam a saída do Reino Unido da União Europeia afirmam que o pertencimento ao bloco limita a soberania do parlamento nacional, principalmente nas áreas de controle de imigração e de negociações comerciais; enquanto os favoráveis à permanência entendem que a relativa perda de soberania é compensada pelos benefícios aferidos dentro do bloco. Ademais, para esses, a saída britânica poderia resultar na diminuição da sua influência no cenário internacional e em possíveis barreiras comerciais entre o Reino Unido e a União Europeia. 
Do ponto de vista político, durante os meses que antecederam a votação, observaram-se divisões entre os partidos e, em especial, internamente no Partido Conservador. De um lado, o UK Independence Party, o Democratic Unionist Party e alguns eurocéticos do Conservative Party fizeram campanha pela saída do Reino Unido do bloco comunitário, com base no argumento de que a participação impõe altas despesas, com pouco retorno ao país. Do outro lado, o ex-primeiro ministro David Cameron e mais quinze membros de seu gabinete, juntamente com o Labour Party, o Liberal Democrats, o Plaid Cymru, o Scottish National Party e mais alguns outros partidos, defenderam a permanência em uma União Europeia reformada, onde o Reino Unido tivesse um status especial, conforme negociado em fevereiro de 2016. A tabela abaixo ilustra o posicionamento dos principais partidos britânicos antes da realização do referendo.

\section{Quadro 1. Posicionamento dos partidos britânicos antes do referendo}

\begin{tabular}{|c|c|}
\hline Posição & Principais Partidos \\
\hline \multirow{2}{*}{ Permanência na UE } & Labour Party \\
& Liberal Democrats \\
& Plaid Cymru \\
\hline Saída da UE & Scottish National Party (SNP) \\
\hline Sem posição oficial & Democratic Unionist Party (DUP) \\
\hline
\end{tabular}

Fonte: elaboração da autora, 2016.

No que se refere ao aspecto geográfico, enquanto a Inglaterra (53,4\% - Leave; 46,6\% - Remain) e o País de Gales (52,5\% - Leave; 47,5\% - Remain) votaram pela saída; na Escócia (38\% - Leave; 62\% - Remain) e na Irlanda do Norte (44,2\% Leave; 55,8\% - Remain), a opção pela permanência na União Europeia recebeu maioria dos votos (BBC, 2017a).

Diante desse cenário, os escoceses, majoritariamente favoráveis à permanência no bloco europeu, afirmaram que pretendem realizar um novo referendo sobre a independência do país. Logo após a divulgação do resultado do referendo, a primeira-ministra do governo escocês, Nicola Sturgeon, declarou que os escoceses deixaram claro que não têm a intenção de sair da União Europeia. O argumento pela permanência no bloco regional já tinha sido utilizado anteriormente por alguns 
grupos políticos, em setembro de 2014, quando a Escócia realizou um referendo sobre a independência do Reino Unido. Naquele momento, permanecer unido aos britânicos significava continuar na União Europeia e, aproximadamente, 55,3\% da população votou contra a independência, enquanto $44,7 \%$ votaram a favor.

O então primeiro-ministro da Irlanda do Norte, Martin McGuinness, afirmou, na época, que o impacto do referendo no país foi muito profundo e que, talvez, a partir daquele momento, toda ilha irlandesa fosse capaz de votar sobre a reunificação. McGuinness renunciou ao cargo de primeiro-ministro em 19 de janeiro de 2017 e faleceu em 21 de março do mesmo ano. Atualmente, a primeira-ministra da Irlanda do Norte é Arlene Foster, do Partido Unionista Democrático, que se aliou ao Partido Conservador de Theresa May para formar maioria parlamentar ${ }^{14}$.

Ainda sobre o aspecto geográfico, vale notar que, em Londres, ao contrário do interior da Inglaterra, a maioria da população votou pela permanência na União Europeia (40\% - Leave; $60 \%$ - Remain) (BBC BRASIL, 2016). Tal fenômeno talvez se explique também pela presença mais constante do bloco europeu no dia a dia dos cidadãos londrinos. Em geral, conforme apontam estudos de especialistas em União Europeia, as elites político-econômicas e a população mais jovem e mais escolarizada, como será explicitado posteriormente, tendem a identificar-se mais com o bloco comunitário, enquanto o restante da população apresenta posturas mais eurocéticas (RISSE, 2003). Isso ocorre, em grande medida, porque os benefícios da integração europeia são mais tangíveis àquele primeiro grupo. Os cidadãos ordinários, isto é, aqueles que não estão envolvidos diretamente com a burocracia da União Europeia, sentem-se mais alijados desse processo de integração, especialmente no caso britânico, em que não há uma cidadania ou uma moeda comum que possam forjar um sentimento maior de identificação com a União Europeia.

Uma das principais divisões acentuadas pelo resultado do referendo reflete a oposição em grupos demográficos nas distribuições tanto por faixa etária quanto por nível de escolaridade. Após o referendo, a diferença entre gerações ficou clara: os mais jovens escolheram a permanência na União Europeia e os mais velhos optaram pela saída. No grupo entre 18 e 24 anos, $73 \%$ votaram pelo Remain, enquanto $60 \%$ dos eleitores acima de 65 anos escolheram o Leave (THE ECONOMIST, 2016).

14 Infelizmente, o relatório do Eurobarometer não tem a segmentação das unidades que compõem o Reino Unido para que seja realizada uma comparação entre os dados sobre o sentimento de identificação com a União Europeia e os resultados do referendo nesse quesito. 
É interessante observar como esse resultado se relaciona com os dados do Eurobarometer, em pesquisa realizada em maio de 2016. Em resposta à pergunta "Você se sente cidadão da União Europeia?", no grupo entre 15 e 24 anos, 70 \% responderam afirmativamente, percentual superior à média europeia (66\%). A população entre 25 e 39 anos também se aproximou dessa média, com $60 \%$ de respostas positivas; todavia, enquanto na faixa entre 40 e 55 anos, $51 \%$ responderam que se sentem cidadãos da União Europeia, apenas $42 \%$ da população acima de 55 anos declarou o mesmo (EUROPEAN COMMISSION, 2016a, p. 33). Nesse sentido, considerando que o Reino Unido integra o bloco comunitário há 45 anos, observa-se que aqueles que nasceram depois de 1973 tendem a identificar-se mais como europeus, aproximando-se da média europeia (66\%), uma vez que sempre estiveram imersos no processo de integração regional.

No que tange ao grau de escolaridade dos eleitores, observa-se também uma segmentação. Por um lado, entre os que têm ensino superior completo, 57\% votaram pela permanência no bloco europeu; por outro lado, a opção pela saída foi majoritária entre a população com baixa escolaridade (THE ECONOMIST, 2016). Mais uma vez, esses resultados são corroborados pelas pesquisas de opinião do Eurobarometer. A população com mais de 20 anos de estudo atingiu percentual acima da média do bloco, com $67 \%$ das respostas afirmativas para a questão "Você se sente cidadão da União Europeia?". Pode-se cogitar, ainda, que esse resultado seja também reflexo da possibilidade que boa parte desses estudantes tiveram em realizar intercâmbios acadêmicos em outros países da União Europeia, beneficiando-se, então, da integração regional. Entre os grupos com menor escolaridade, enquanto $50 \%$ daqueles que têm entre 16 e 19 anos de estudo responderam afirmativamente, somente $28 \%$ dos com menos de 15 anos de estudo adotaram posição semelhante (EUROPEAN COMMISSION, 2016a, p. 33).

É possível analisar, ademais, como cada um desses segmentos estratificados por faixa etária e por nível de renda respondeu ao questionamento "Você se identifica como...?”. A Tabela 3 traz uma síntese desses dados, comparando os percentuais da média europeia com os britânicos. Dessa forma, pode-se verificar como os altos índices de nacionalismo, pela escolha da opção "apenas nacional”, se concentram nos grupos mais velhos - $73 \%$ da população acima de 55 anos e com menor escolaridade $-85 \%$ dos entrevistados com menos de quinze anos de estudo, correspondendo àqueles que majoritariamente votaram pela saída do Reino Unido da União Europeia. 
Tabela 3. Percentual de respostas ao questionamento "Você se identifica como...?" - estratificação por faixa etária e escolaridade em maio de 2016

\begin{tabular}{lcccccccc}
\hline & \multicolumn{2}{c}{ Apenas nacional } & \multicolumn{2}{c}{ Nacional e europeu Europeu e nacional } & Apenas europeu \\
\cline { 2 - 9 } & UE & Reino Unido & UE & Reino Unido & UE & Reino Unido & UE & Reino Unido \\
\hline Faixa etária (anos) & & & & & & & \\
\hline $15-24$ & $32 \%$ & $54 \%$ & $55 \%$ & $35 \%$ & $8 \%$ & $2 \%$ & $2 \%$ & $3 \%$ \\
$25-39$ & $34 \%$ & $55 \%$ & $54 \%$ & $37 \%$ & $8 \%$ & $3 \%$ & $1 \%$ & $1 \%$ \\
$40-54$ & $35 \%$ & $57 \%$ & $56 \%$ & $36 \%$ & $6 \%$ & $3 \%$ & $1 \%$ & $1 \%$ \\
acima de 55 & $47 \%$ & $73 \%$ & $46 \%$ & $22 \%$ & $4 \%$ & $2 \%$ & $1 \%$ & $0 \%$ \\
\hline Escolaridade (anos) & & & & & & $1 \%$ & $1 \%$ & $0 \%$ \\
\hline menos de 15 & $58 \%$ & $85 \%$ & $37 \%$ & $11 \%$ & $2 \%$ & $1 \%$ & $1 \%$ \\
$16-19$ & $43 \%$ & $69 \%$ & $49 \%$ & $25 \%$ & $5 \%$ & $1 \%$ & $2 \%$ & $2 \%$ \\
\hline
\end{tabular}

Fonte: elaboração da autora baseado em European Commission, 2016a.

Neil Fligstein (2008), no livro Euroclash, apontou o que poderia conduzir a um processo de embate na integração europeia e ao aumento do euroceticismo. Com a intensificação da integração social e econômica da União Europeia, seria cada vez mais evidente discernir os vencedores e os perdedores desse processo. No grupo dos vencedores, pode-se identificar aqueles que tiveram um incremento no seu bem-estar social, com o aumento da renda, o acesso a empregos mais bem qualificados, a facilidade na circulação entre os países do bloco, as possibilidades de intercâmbio acadêmico etc., por conta do processo de integração regional. Entre os perdedores estão as populações que não aferiram tantos benefícios da Europa comunitária e sentiram efeitos adversos, a exemplo do crescimento do desemprego. Enquanto os vencedores, de maneira geral, apoiariam o aprofundamento da integração regional, os perdedores, por sua vez, tenderiam a exacerbar mais o nacionalismo e a opor-se às políticas comunitárias que não os favorecessem. Fligstein (2008) enumerou alguns pontos que pressionariam pelo fortalecimento do nacionalismo, em detrimento do supranacionalismo, e que, de fato, foram utilizados na campanha pela saída da União Europeia. Um dos exemplos é a questão da imigração e dos benefícios sociais:

As questões políticas continuarão a dividir os cidadãos em diferentes países. A imigração é uma das questões mais inflamadas que empurra a identidade nacional para frente (...) Uma ênfase contínua na identidade nacional reflete não 
apenas preocupações culturais, mas também econômicas. O envelhecimento da população exercerá mais pressão sobre os governos para que continuem a apoiar as estruturas do Estado de bem-estar social e usar o governo nacional para proteger o emprego, os cuidados de saúde e as pensões. (FLIGSTEIN, 2008, p. 253, tradução nossa) ${ }^{15}$

Conforme sinalizou o autor, a decisão sobre o futuro da Europa comunitária estaria nas mãos dos eleitores de classe média16, que veem o projeto de integração econômica da União Europeia como algo bom, mas que se preocupam com os efeitos sobre seus benefícios sociais e sobre as oportunidades de emprego. Como indicado pela realidade fática, esses foram alguns dos principais focos da campanha do Leave para convencer o eleitorado britânico a optar pela saída do bloco regional. Esse mesmo cenário de fortalecimento do nacionalismo e de aumento do euroceticismo pode ocorrer em outros países membros do bloco e conduzir a novos embates dentro do processo de integração europeia. A opção britânica pela saída abriu um novo precedente, que pode ou não ser seguido por outras populações insatisfeitas com a integração regional.

A principal fonte de tensão e conflito sobre o que acontece na Europa é a diferença entre aqueles que participam e se beneficiam diretamente da Europa e aqueles que não (...) Dado o fato de que os beneficiários da maior interação foram as pessoas mais ricas e mais educadas, a "Europa” torna-se um grande alvo potencial para os políticos e para parte da população que não se considera europeia. Esses cidadãos podem facilmente ver a integração europeia tanto como um plano de negócios que beneficie aqueles que já estão em melhor situação ou como um assalto à sua identidade nacional, à soberania do Estado e ao estado de bem-estar. (FLIGSTEIN, 2008, p. 4, tradução nossa) ${ }^{17}$

15 Political issues will continue to divide citizens in different countries. Immigration is one of the most inflammatory issues that pushes national identity to the fore (...) A continued emphasis on national identity reflects not just cultural concerns but also economic ones. The aging of the population will put more pressure on governments to continue to support welfare state structures and use the national government to protect employment, healthcare, and pensions.

16 O resultado do referendo britânico confirma, em alguma medida, o argumento de Fligstein, uma vez que as regiões com renda anual mais baixa votaram pela saída, conforme dados do jornal The Guardian (2016).

17 The main source of tension and conflict over what happen next in Europe is the gap between those who participate and benefit from Europe directly and those who do not (...) Given the fact that the beneficiaries of much interaction have been people who are richer and more educated, 'Europe' makes a big potential target for politicians and much of the population who do not think of themselves as Europeans. These citizens can easily view European integration as either a business plot that benefits those who are already better off or an assault on their national identity, state sovereignty, and welfare state. 
De fato, o referendo britânico evidenciou essa disparidade (THE GUARDIAN, 2016). Os dados estatísticos referentes ao plebiscito e às pesquisas de opinião do Eurobarometer sobre aspectos identitários revelam a fragmentação que existe dentro do Reino Unido; todavia, o relatório do Eurobarometer de novembro de 2016 demonstra que houve um arrefecimento, em todas as faixas etárias e em todos os níveis de escolaridade, da opção "apenas nacional”, em comparação com a pesquisa anterior, conforme evidencia a Tabela 4 .

Tabela 4. Percentual de respostas ao questionamento "Você se identifica como...?" - estratificação por faixa etária e escolaridade em novembro de 2016

\begin{tabular}{|c|c|c|c|c|c|c|c|c|}
\hline & \multicolumn{2}{|c|}{ Apenas nacional } & \multicolumn{2}{|c|}{ Nacional e europeu } & \multicolumn{2}{|c|}{ Europeu e nacional } & \multicolumn{2}{|c|}{ Apenas europeu } \\
\hline & UE & Reino Unido & UE & Reino Unido & UE & Reino Unido & UE & Reino Unido \\
\hline \multicolumn{9}{|c|}{ Faixa etária (anos) } \\
\hline $15-24$ & $28 \%$ & $40 \%$ & $58 \%$ & $43 \%$ & $8 \%$ & $10 \%$ & $2 \%$ & $1 \%$ \\
\hline $25-39$ & $30 \%$ & $37 \%$ & $57 \%$ & $52 \%$ & $8 \%$ & $6 \%$ & $2 \%$ & $2 \%$ \\
\hline $40-54$ & $34 \%$ & $45 \%$ & $56 \%$ & $44 \%$ & $6 \%$ & $8 \%$ & $2 \%$ & $2 \%$ \\
\hline acima de 55 & $45 \%$ & $61 \%$ & $47 \%$ & $29 \%$ & $4 \%$ & $4 \%$ & $2 \%$ & $3 \%$ \\
\hline \multicolumn{9}{|c|}{ Escolaridade (anos) } \\
\hline menos de 15 & $56 \%$ & $70 \%$ & $37 \%$ & $23 \%$ & $4 \%$ & $3 \%$ & $1 \%$ & $2 \%$ \\
\hline $16-19$ & $40 \%$ & $56 \%$ & $51 \%$ & $35 \%$ & $5 \%$ & $4 \%$ & $2 \%$ & $2 \%$ \\
\hline mais de 20 & $23 \%$ & $28 \%$ & $64 \%$ & $56 \%$ & $9 \%$ & $10 \%$ & $2 \%$ & $2 \%$ \\
\hline
\end{tabular}

Fonte: elaboração da autora baseado em European Commission, 2016b.

Nesse sentido, observa-se, nos níveis de estratificação por faixa etária e por escolaridade, fenômeno semelhante ao apontado na seção anterior, com a diminuição da opção "apenas nacional” em substituição à identificação com opções que incluem também o sentimento de europeidade, mesmo entre a população mais idosa e entre a parcela dos entrevistados com menor nível de escolaridade. Na faixa que reúne aqueles com mais de 55 anos, houve uma redução de doze pontos percentuais (de $73 \%$ para $61 \%$ ) no montante de entrevistados que se identificam somente como britânicos; e, para aqueles com menos de 15 anos de estudos, a contração foi ainda maior, correspondendo a uma queda de quinze pontos percentuais (de 85\% para 70\%) (EUROPEAN COMMISSION, 2016b, p. 39). 


\section{O atual cenário político no Reino Unido}

Conforme demonstrado, observou-se uma grande mudança nas pesquisas realizadas antes e depois do referendo, no que diz respeito à parcela da população que tende a identificar-se tanto como nacional quanto como europeia. O resultado das eleições gerais para o Parlamento Britânico, convocadas pela primeira-ministra Theresa May com o intuito de aumentar a sua base de apoio para negociar a saída da União Europeia, evidenciam, em alguma medida, as mudanças que estão processando-se no interior do Reino Unido desde o resultado do referendo.

Nas eleições de 8 de junho de 2017, o Partido Conservador, comandado por May, deixou de ter a maioria parlamentar ao perder treze cadeiras e precisou aliar-se aos unionistas democráticos da Irlanda do Norte, com dez assentos, para formar o governo. O Partido Trabalhista, liderado por Jeremy Corbyn, conquistou trinta cadeiras adicionais, consolidando-se como a segunda força no Parlamento Britânico, enquanto o Partido Nacional Escocês (SNP) foi o mais prejudicado, com a perda de vinte e um assentos. É interessante analisar que, no caso da Escócia, as cadeiras que eram do SNP foram redistribuídas entre os conservadores (12), os trabalhistas (6) e os liberais democratas (3), o que, de alguma forma, reduz a força do pleito escocês pela realização de um novo referendo pela independência do país, já que o SNP não conta mais com uma representação considerável dentro do parlamento (BBC, 2017b).

Conforme mencionado, o Partido Trabalhista foi quem mais se fortaleceu com as eleições gerais, e muito se deve à força de Corbyn em angariar a participação da população mais jovem, especialmente a inglesa, nas eleições, o que não ocorreu em larga escala no referendo britânico. Dos trinta assentos adicionais conquistados pelos trabalhistas, vinte e um provieram de distritos eleitorais da Inglaterra, onde o Partido Conservador perdeu vinte e duas cadeiras. Esse enfraquecimento do Partido Conservador e a necessidade de Theresa May em aliar-se aos unionistas podem limitar a capacidade de negociação da primeira-ministra, que vem propondo um hard Brexit no processo para saída da União Europeia (BBC, 2017b).

Em 19 de junho de 2017, quase um ano depois do referendo britânico, iniciaram-se, em Bruxelas, as negociações entre o Reino Unido e a União Europeia para a retirada do país do bloco regional. Ambos os lados têm até 29 de março de 2019, quando se completam dois anos da entrega da carta que acionou o artigo 50 do Tratado de Lisboa, para chegar a um acordo sobre as condições para saída do bloco e o futuro do relacionamento entre os britânicos e a Europa 
comunitária; todavia, o mesmo artigo também prevê a possibilidade de prorrogação do prazo em decisão unânime entre o Conselho Europeu e o Estado membro em questão. Em março de 2018, foi definido um período de transição até 31 de dezembro de 2020 para a efetiva saída do Reino Unido das instituições europeias, entretanto, o país já não terá mais poder de voto a partir de 29 de março de 2019 (EUROPEAN COMMISSION, 2018).

Nesse curto espaço de tempo desde o referendo, ocorreram muitas mudanças no interior do Reino Unido, como a renúncia de David Cameron e a posse de Theresa May; as mudanças no sentimento de identificação com a União Europeia, conforme demonstrado neste artigo, em consonância com os relatórios do Eurobarometer; e, mais recentemente, os resultados das eleições gerais e o pedido de May por um período extra para a transição após o fim das negociações ${ }^{18}$. Considerando esses aspectos, não se pode prever de antemão os resultados do processo de negociação para a saída britânica, que tende a ser extenuante e, com base no histórico recente de inconstâncias, permeado por novas transformações que poderão ainda vir a ocorrer.

\section{Conclusões}

O histórico do relacionamento do Reino Unido com a União Europeia sempre foi marcado por entraves e pelo baixo envolvimento do país nos mecanismos de aprofundamento institucional, preferindo negociar opções de exclusão à legislação comunitária, como é o caso da União Econômica e Monetária e do Acordo Schengen. Ainda que seja necessário investigar detalhadamente, em pesquisas futuras, os opt-outs britânicos no processo de integração regional, uma análise pontual de dois momentos específicos, antes e depois do referendo, permite identificar uma das possíveis variáveis que explicam a opção pela saída da União Europeia: as percepções identitárias.

Com base no exposto no artigo, é possível relacionar a identidade europeia às atitudes do Reino Unido no que se refere ao processo de integração regional e, particularmente, ao resultado do referendo de junho de 2016. Os dados do Eurobarometer, especialmente da pesquisa realizada em maio de 2016, cerca de um

18 Conforme decisão do Conselho Europeu, esse período não seria superior a 21 meses: de 29 de março de 2019 a 31 de dezembro de 2020 (EUROPEAN COMMISSION, 2018). 
mês antes do referendo britânico, tendem a corroborar a ideia de que o sentimento de identificação com a União Europeia e o suporte ao processo de integração regional são variáveis correlacionadas. Naquele momento, o Reino Unido era o Estado membro que apresentava o menor grau de europeidade, entendida com base na identificação como cidadão da União Europeia, e o maior percentual de identificação como “apenas nacional”. A vitória, na consulta popular, da opção pela saída do bloco comunitário reflete essa fraca identidade europeia no país.

Ademais, verificou-se também a correspondência entre as percepções identitárias e os resultados do referendo estratificados por faixa etária e nível de escolaridade. A população mais idosa e com menos anos de estudo, que votou majoritariamente pelo Leave, tende a identificar-se menos como europeia, o que comprova o argumento de que esses são os que menos sentem a presença da Europa comunitária em seu cotidiano e pouco se beneficiam da integração regional.

Apesar da correlação observada entre identidade europeia e suporte ao processo de integração, os resultados da pesquisa de opinião realizada após o referendo indicam uma mudança jamais observada anteriormente na identificação britânica com a União Europeia. Em menos de seis meses, entre maio e novembro de 2016, 14\% da população do Reino Unido que se classificava como apenas nacional passou a se identificar também como europeia. Esse é um fenômeno ainda recente, que merece uma análise mais aprofundada. A comparação com os resultados das pesquisas vindouras, especialmente as que serão realizadas durante o processo de negociação para a saída do Reino Unido da União Europeia, poderá auxiliar na melhor compreensão dessa temática.

\section{Referências}

BBC. The UK's EU referendum: All you need to know. 2017a. Disponível em: < http://www.bbc.com/news/uk-politics-32810887 > . Acesso em: 03 out. 2017.

BBC. Results of 2017 General Election. 2017b. Disponível em: < http://www.bbc.com/ news/election/2017/results > . Acesso em: 03 out. 2017.

BBC BRASIL. Plebiscito revela 'Reino Desunido' e fosso entre gerações. 24 junho 2016. Disponível em: < http://www.bbc.com/portuguese/internacional-36617121 > . Acesso em: 03 out. 2017.

BRUTER, Michael. Citizens of Europe? The emergence of a Mass European Identity. Palgrave Macmillan: New York, 2005. 
CHECKEL, Jeffrey T.; KATZENSTEIN, Peter J. (ed.) European Identity. Cambridge University Press, 2009.

EUROPEAN COMMISSION. European citizenship. Standard Eurobarometer 77, Spring, May 2012a.

EUROPEAN COMMISSION. European citizenship. Standard Eurobarometer 78, Autumm, November 2012b.

EUROPEAN COMMISSION. European citizenship. Standard Eurobarometer 79, Spring, May 2013a.

EUROPEAN COMMISSION. European citizenship. Standard Eurobarometer 80, Autumm, November 2013b.

EUROPEAN COMMISSION. European citizenship. Standard Eurobarometer 81, Spring, June 2014a.

EUROPEAN COMMISSION. European citizenship. Standard Eurobarometer 82, Autumm, November 2014b.

EUROPEAN COMMISSION. European citizenship. Standard Eurobarometer 83, Spring, May 2015a.

EUROPEAN COMMISSION. European citizenship. Standard Eurobarometer 84, Autumm, November 2015b.

EUROPEAN COMMISSION. European citizenship. Standard Eurobarometer 85, Spring, May 2016a.

EUROPEAN COMMISSION. European citizenship. Standard Eurobarometer 86, Autumm, November 2016b.

EUROPEAN COMMISSION. Public Opinion in the European Union. First Results. Standard Eurobarometer 87, Spring, May 2017.

EUROPEAN COMMISSION. Brexit negotiations. 2018. Disponível em: < https://ec.europa. eu/commission/brexit-negotiations_en > . Acesso em: 20 abr. 2018.

FLIGSTEIN, Neil. Euroclash: The EU, European Identity, and the Future of Europe. Oxford: University Press, 2008.

FUCHS, Dieter; KLINGEMANN, Hans-Dieter (eds.). Cultural Diversity, European Identity and the Legitimacy of the EU. Cheltenham, UK; Northampton, USA: Edward Elgar, 2011. GEORGE, Stephen. British Policy in the European Community: the commitment to globalism. University of Sheffield, UK, 1991.

HILMARSSON, Hilmar Pór. Exit Brexit, Voice and Loyalty. Social Europe, December $18^{\text {th }}$, 2017. Disponível em:<https://www.socialeurope.eu/exit-brexit-voice-loyalty > . Acesso em: 20 abr. 2018.

HIRSCHMAN, Albert O. Exit, Voice and Loyalty: Responses to Decline in Firms, Organizations and States. Cambridge, Massachusetts and London: Harvard University Press, 1970. 
PERISIC, Bojana. Britain and Europe: a history of difficult relations. Institute for Cultural Diplomacy, Berlin, March 2010.

RISSE, Thomas. European institutions and identity change: what have we learned? In: HERRMANN, Richard; BREWER, Marylinn, RISSE, Thomas (eds). Identities in Europe and the institutions of European Union. Lanhan MD: Rowman \& Littlefield, 2003.

RISSE, Thomas. Neo-functionalism, European Identity, and the Puzzles of European Integration. Journal of European Public Policy, Special Issue, 2005.

THATCHER, Margaret. The Bruges Speech. Speech to the College of Europe, September 20th, 1988. Disponível em: < http://www.margaretthatcher.org/document/107332 > . Acesso em: 03 out. 2017.

THE ECONOMIST. Britain votes to leave EU. June $24^{\text {th }}$, 2016. Disponível em: < http://www.economist.com/blogs/graphicdetail/2016/06/daily-chart-17 > . Acesso em: 01 out. 2017.

THE GUARDIAN. EU referendum: full results and analysis. 2016. Disponível em: < https://www.theguardian.com/politics/ng-interactive/2016/jun/23/eu-referendumlive-results-and-analysis > . Acesso em: 20 abr. 2018.

WASHINGTON POST. The British are frantically Googling what the E.U. is hours after voting to leave it. June $24^{\text {th }}$, 2016. Disponível em: < https://www. washingtonpost. com/news/the-switch/wp/2016/06/24/the-british-are-frantically-googling-whatthe-eu-is-hours-after-voting-to-leave-it/?utm_term $=. d b 443189 a 77 a>$. Acesso em: 03 out. 2017. 